\title{
Objectively-assessed physical activity and weight change in young adults: a randomized controlled trial
}

\author{
Jessica L. Unick ${ }^{1 *}$, Wei Lang ${ }^{2}$, Samantha E. Williams', Dale S. Bond', Caitlin M. Egan', Mark A. Espeland²,
} Rena R. Wing ${ }^{1}$, Deborah F. Tate ${ }^{3}$ and SNAP Research Group

\begin{abstract}
Background: Reductions in physical activity (PA) are common throughout young adulthood and low PA is associated with weight gain. The SNAP Trial previously reported that two self-regulation approaches to weight gain prevention reduced weight gain over a 2-year period in 18-35 year olds. Presented here are secondary analyses examining changes in PA and the relationship between PA and weight change over 2 years.

Methods: 599 young adults (age: $27.4 \pm 4.4 \mathrm{yrs}$.; BMl: $25.4 \pm 2.6 \mathrm{~kg} / \mathrm{m}^{2}$ ) were randomly assigned to 1 of 3 treatment arms: Small Changes (reduce calorie intake by $100 \mathrm{kcals} /$ day \& add $2000 \mathrm{steps} /$ day), Large Changes (lose $2.3-4.5 \mathrm{~kg}$ initially \& increase PA to $\geq 250 \mathrm{~min} / \mathrm{wk}$ ), or Self-guided (control condition). Small and Large Changes received 10, face-to-face group sessions (months 1-4), and two 4-week refresher courses each subsequent year. Body weight and PA were objectively-measured at baseline, 4 months, 1 and 2 years. Daily steps and bout-related moderate-to-vigorous intensity PA (MVPA: $\geq 3$ METs, $\geq 10$-min bouts) was calculated.
\end{abstract}

Results: Changes in bout-related MVPA and daily steps did not differ among treatment groups over the 2-year period ( $p$ 's $>0.16)$. Collapsed across groups, participants gaining $>1 \mathrm{lb} .(n=187 ; 39.6 \%)$ had smaller changes in bout-related MVPA at 4 months, 1 and 2 years relative to those maintaining or losing weight ( $\leq 1 \mathrm{lb}$. weight gain; $n$ $\left.=282,60.4 \%, p^{\prime} s<0.05\right)$. Averaged across time points, this difference equated to $47.8 \mathrm{~min} /$ week. Those gaining and not gaining $>1 \mathrm{lb}$. did not differ on daily steps ( $p$ 's $>0.10$ ). Among participants engaging in $\geq 250 \mathrm{~min} / \mathrm{wk}$. of MVPA at 2 years $(n=181), 30 \%$ gained $>1 \mathrm{lb}$. from baseline to 2 years, which was not different from those engaging in $150-250 \mathrm{~min} / \mathrm{wk}$. ( $n=87 ; 36 \% ; p=0.40)$, but this percentage was significantly lower when compared to those engaging in $<150 \mathrm{~min} / \mathrm{wk}$. $(n=176 ; 49 \% ; p<0.001)$.

Conclusions: On average, PA differences were not observed between young adults assigned to small or large changes self-regulation interventions to prevent weight gain. Regardless of group assignment, higher levels of MVPA were associated with better weight gain prevention over 2 years. Our data suggest that achieving $>150 \mathrm{~min} /$ week of MVPA is needed for weight gain prevention and that increasing MVPA, rather than steps, should be targeted.

Trial registration: www.clinicaltrials.gov (NCT01183689). Registered Aug 13, 2010.

Keywords: Weight gain, Young adulthood, Exercise, Physical activity, Body weight

\footnotetext{
* Correspondence: junick@lifespan.org

'Brown University and the Miriam Hospital's Weight Control and Diabetes

Research Center, 196 Richmond Street, Providence, RI 02903, USA

Full list of author information is available at the end of the article
} 


\section{Background}

Previous literature demonstrates that young adults (ages 18-35) experience a faster rate of weight gain than other age groups, gaining an average of $1 \mathrm{lb}$./year [1, 2]. This is of concern given that rapid weight gain among young adults has been linked to elevated cardiovascular disease risk factors and other adverse health outcomes [3]. Of additional concern is that a higher BMI earlier in life is associated with having a higher BMI later in life $[4,5]$. Thus preventing weight gain throughout young adulthood could have significant public health implications.

Young adulthood is also marked by reductions in physical activity (PA), which typically begin during adolescence and continue throughout young adulthood. This is a highly transitional period, often characterized by significant life events (e.g., starting a new job, getting married, or having children); thus it is possible that these major life transitions may be a contributing factor to the observed decrease in PA [6, 7] and subsequent weight gain $[8,9]$. Currently, the role of PA in weight gain prevention among young adults is not currently understood. According to the American College of Sports Medicine, there is adequate evidence that 150-250 min/ week of moderate-to-vigorous intensity PA (MVPA) is sufficient to prevent significant weight gain in the general population [10]. Given that weight gain is most common in young adults, it is unclear whether this magnitude of PA is also sufficient for preventing weight gain in this age group.

To date, the body of literature related to PA and weight gain among young adults is limited. The majority of studies have been cross-sectional (i.e., comparing PA patterns in young adults to other age groups) or longitudinal (i.e., examining changes in PA over time within a cohort of individuals) [7, 11-13] and few intervention studies have been conducted. Thus, little is known about how PA and body weight change within the context of a lifestyle intervention or whether changes in PA are related to changes in body weight among young adults. An additional concern is that the majority of PA studies have utilized self-reported measures of PA, which are prone to participant biases due to social desirability or imprecise recall [14]; thus it is unclear whether similar findings would be observed when objective PA measures were used. Given these significant gaps in the literature, coupled with the high risk nature of weight gain among this demographic group, it is evident that well-designed intervention studies aimed at increasing PA and preventing weight gain are needed. Studies such as these are critical for determining whether objectively-assessed PA is improved as a result of lifestyle intervention in young adults and whether changes in PA are related to changes in body weight.

The Study of Novel Approaches to Weight Gain Prevention (SNAP) trial overcomes some of these previous limitations and provides an excellent opportunity to examine the relationship between objectively-assessed PA and weight change over a 2-year period among young adults interested in weight gain prevention. The SNAP trial compared two self-regulation weight gain prevention programs (e.g., 'Large Changes' and 'Small Changes') to a minimal contact control condition (i.e., 'Self-Guided') over a two-year period. The primary aim was to examine changes in weight across the three intervention arms, and these data have been previously published [15]. The current analyses focus on whether there was a differential effect of intervention arm on objectivelyassessed PA over the 2-year period and whether compliance to the PA recommendations differed by group. Secondary aims were to examine the impact of baseline PA on changes in PA over time and to determine whether there is a relationship between PA and weight gain prevention over the intervention period.

\section{Methods \\ Participants}

Young adults $(n=599)$ interested in weight gain prevention enrolled in the SNAP trial between August 2010 and February 2012. Participants were recruited primarily by mass mailings (38\%) and emails (23\%), using text that sought individuals who were concerned about gaining weight over time [16]. Participants were normal weight (BMI: 21 to $<25 \mathrm{~kg} / \mathrm{m}^{2}$ ) or overweight (BMI: 25 to $30 \mathrm{~kg}$ / $\mathrm{m}^{2}$ ), between the ages of 18 and 35, English speaking, and had no medical conditions that would limit their ability to make dietary or PA changes. Eligible individuals were required to pass screening and baseline assessment visits. Full exclusion criteria have been previously reported [17].

\section{Design}

The SNAP trial examined two novel interventions for weight gain prevention compared to a control condition in young adults. Participants were randomized to one of three treatment arms: Small Changes (SC), Large Changes (LC) or Self-Guided (SG), which served as the control condition. Participants in LC and SC received a lifestyle intervention for 4 months (10 face-to-face group meetings), followed each year by two four-week refresher courses delivered primarily via the Internet. A detailed description of these treatment groups has been reported previously [17] and intervention components are also summarized below. All groups completed assessment visits at baseline, 4 months, 1 year, and 2 years post-treatment. Informed consent was obtained from all participants, and procedures were performed in accordance with The Miriam Hospital's (Providence, RI) and University of North Carolina (Chapel Hill, NC) Institutional Review Boards.

\section{Randomization}

Randomization assignment used variable block lengths, was stratified by clinical site, sex, and ethnicity (non-Hispanic white/other), and was implemented through a web-based data management system. 


\section{Treatment groups \\ Intervention components common to both large changes and small changes}

Participants randomized to LC or SC attended weekly inperson, group-based sessions for 8 weeks, followed by 2 monthly sessions, and were offered two 4-week, online refresher courses for each successive year of the study. While dietary and PA recommendations differed between SC and LC, both treatment groups emphasized daily self-weighing and participants were instructed to record their weight daily throughout the course of the study. Self-regulation techniques, such as detecting small changes in weight as soon as they occur and implementing problem solving and behavioral strategies to counteract the weight gain, were used in both groups.

\section{Small changes}

Participants randomized to SC were instructed to make daily, small changes in diet and PA in order to prevent weight gain. Dietary recommendations focused on reducing calorie intake by 100 cal per day through 'small' behavior modifications, such as reducing portion sizes or selecting lower calorie alternatives. Further, SC participants were given pedometers and instructed to increase daily steps by 2000 steps/day above their baseline level (equivalent to 1 mile of walking) through changes in lifestyle activities (e.g., parking further from the store or using the stairs). Participants were given a monthly chart to record their daily weight, steps, and whether they made any small changes to their diet. This was completed daily during the first 16 weeks and during refresher courses. These were reviewed by interventionists and feedback was provided.

\section{Large changes}

Participants randomized to $\mathrm{LC}$ were instructed to make larger changes to their diet and PA to create a 5 to 10 pound buffer against future weight gain within the first 4 months [18]. Participants were instructed to reduce calorie intake by 500-1000 kcals/day (depending upon initial body weight) and increase PA gradually to $\geq 250 \mathrm{~min} /$ week of MVPA. Once this 'buffer' was created, participants were instructed to gradually increase calorie intake to maintain their reduced weight and to maintain this high level of PA throughout the remainder of the study. If at any point a participant's weight exceeded their baseline weight, it was recommended that they return to their initial calorie intake and recreate another 5-10 lb. buffer. Participants were instructed to record their weight, diet, and minutes of PA daily. These diaries were reviewed by an interventionist and feedback was provided.

\section{Self-guided (control condition)}

Participants in the control condition attended one in-person group session and were provided with general information on weight gain in young adults, which included basic guidelines for self-weighing and a brief overview of both SC and LC approaches. They were then encouraged to select the approach that would work best for them and apply these strategies over the course of the study. Participants were sent quarterly newsletters via postal mail and were provided with links to internet resources via a study website but received no additional contact from intervention staff.

\section{Assessments}

All assessments were completed by masked staff members, who were centrally trained and certified.

\section{Anthropometric}

Height and weight were measured at baseline, 4 months, 1 year, and 2 years. Height was measured using a wallmounted stadiometer and weight was measured in light clothing without shoes on a calibrated scale.

\section{Dietary intake}

Dietary intake was assessed at baseline, 4 months, and 2 years using the Block Food Frequency Questionnaire [19]. Dietary comparisons between treatment arms will be reported in a separate manuscript. However, total daily caloric intake and percentage of total calories from dietary fat were controlled for in all analyses which assessed the relationship between PA and weight change.

\section{Physical activity}

Physical activity was assessed using the previously validated Sensewear Armband (SWA, BodyMedia, Pittsburgh, PA) [20-22]. The SWA is worn on the back of the upper arm and assesses PA using a biaxial accelerometer and a combination of heat sensors. Participants were instructed to wear the device during all waking hours (except while bathing or swimming) for 7 consecutive days at each assessment time point and data were considered to be 'valid' if wear time was $\geq 8 \mathrm{~h}$ on $\geq 4$ days. Proprietary algorithms produced minute-by-minute estimates of energy expenditure (expressed as metabolic equivalents or METs) using the Sensewear Professional Software (Version 7.0). These MET values were used to calculate 'bout-related' moderate-tovigorous intensity PA (MVPA), which includes activities $\geq 3.0$ METs and $\geq 10 \mathrm{~min}$ in duration. Further the SWA provided estimates of daily steps. The proportion of participants meeting the national PA recommendation for improved health (e.g., $\geq 150 \mathrm{~min} /$ week of bout-related MVPA [23]), weight control ( $\geq 250 \mathrm{~min} /$ week of bout-related MVPA [10]), and daily steps (10,000 steps/day [24]) were also examined.

\section{Statistical analyses}

Data were analyzed between May 2016 and February 2017. Statistical analyses were performed using SAS (version 9.4). The type I error rate was fixed at 0.05 (two-tailed). Descriptive statistics included mean and standard deviation (SD) or 
median and interquartile range (IQR) for continuous measures, depending on the normality of distribution, and count and percentage for categorical variables.

To examine differences among the three treatment groups in the changes of daily steps, bout-related MVPA, and body weight, separate mixed effects models were fit to the changes from baseline in these outcomes, with three time points (4 months, 1- and 2- years). Each model was adjusted for the following covariates: clinic, gender, race (White vs. non White), and baseline value of the corresponding outcome. Both mixed effects models for the changes of daily steps and bout-related MVPA also adjusted for the time-varying covariate of armband wear time. Significance of treatment group, time, and treatment group by time interaction effects were assessed in these models using the unstructured dependence structure. Results from the mixed model analyses were presented as the least square mean with 95\% confidence interval.

Dichotomous outcomes were defined over time for meeting $\geq 250 \mathrm{~min} /$ week of bout-related MVPA and for increasing daily steps by $\geq 2000$ steps/day. Subsequently, these dichotomous outcomes were modeled using the generalized estimating equations (GEE) approach, adjusting for covariates of clinic, gender, race (White vs. non White), armband wear time, and baseline value of either bout-related MVPA or daily steps.

The Wilcoxon rank sum test was used to test the differences in changes in daily steps and bout-related MVPA between two groups: those who gained $>1 \mathrm{lb}$. and those who gained $\leq 1 \mathrm{lb}$. or lost weight from baseline to 2 years. A binary indicator variable $(=1$ if gained $>1 \mathrm{lb}$. from baseline to 2 years, $=0$ otherwise) was added to the mixed effects models described above. This model also adjusted for dietary intake covariates (total daily caloric intake and percentage of total calories from dietary fat). Regression coefficient, standard error, and $p$-value for the binary indicator are presented in Table 3.

\section{Results \\ Participants}

Subject characteristics have been described in detail previously [17]. At baseline, four participants failed to meet the minimal armband wear time criteria, resulting in analysis sample of $n=595$. Participants were predominately white (73\%) and female (78\%), $27.7 \pm 4.4$ years of age, with a mean BMI of $25.4 \pm 2.6 \mathrm{~kg} / \mathrm{m}^{2}$. Participants with weight data and those meeting the minimal armband wear time threshold at each time point were included in the analyses (baseline: 99\%, 4 months: 92\%, 1 year: 79\%, 2 years: 76\% of participants) and retention rates did not differ by treatment arm at any time point ( $p$ s $>0.08$, see Appendix 1 Consort diagram and Additional file 1: checklist). Compliance to wearing the armband was excellent at baseline (7.1 \pm 0.9 days for $14.1 \pm 1.5 \mathrm{~h} /$ day) and remained high at 4 months ( $6.6 \pm 1.3$ days for $13.7 \pm 1.8 \mathrm{~h}$ /day), 1 year (6.6 \pm 1.4 days for $13.7 \pm 1.8 \mathrm{~h} /$ day $)$ and 2 years $(6.6 \pm 1.4$ days for $13.6 \pm 1.6 \mathrm{~h} /$ day). On average, study participants were highly active at baseline with $60.2 \%$ achieving $\geq 150 \mathrm{~min} /$ week of bout-related MVPA, $40.8 \%$ achieving $\geq 250 \mathrm{~min} /$ week of bout-related MVPA, and $28.4 \%$ averaging the national recommendation for daily steps $(\geq 10,000$ steps/ day). Attendance at face-to-face intervention meetings did not differ between SC (86.0\%) and LC (87.4\%).

\section{Change in physical activity throughout the intervention by treatment arm}

The primary aim was to examine whether there was a differential effect of treatment arm on objectively-assessed PA over the 2-year period. The group by time interaction effect was not significant, indicating that the pattern of change over time for both daily steps and bout-related MVPA did not differ between treatment arms (Table 1). Further, in models adjusting for demographic variables, 4month, 1-year, and 2-year change in daily steps and boutrelated MVPA did not significantly differ across treatment groups. However, there was a significant time effect such that, when collapsed across treatment arms, changes in daily steps at month 4 was significantly greater than changes at year $1(p=0.015)$ and year $2(p=0.006)$, while changes in weekly bout-related MVPA was significantly greater at 4 months compared to year $1(p=0.013)$.

Compliance to the intervention PA recommendations for LC ( $\geq 250 \mathrm{~min} /$ week of bout-related MVPA) and SC (increase steps by $\geq 2000$ steps/day) was also assessed within treatment arms. The percentage of participants engaging in $\geq 250 \mathrm{~min} /$ week of bout-related MVPA did not change over the 2-year intervention period and did not differ between treatment groups (Table 2). Further, the percentage of participants increasing their steps by $\geq 2000$ steps/day above baseline did not change over time or differ by treatment arm (Table 2). Finally, attendance at intervention meetings was not associated with the change in daily steps or change in MVPA at any time point (e.g., 1-year: SC: steps: $r=0.10$, $p=0.24$, MVPA: $r=-0.05, p=0.57$; or 1-year LC steps: $r=$ $0.09, p=0.23$, MVPA: $0.14, p=0.07$ ).

\section{Effect of baseline physical activity on change in physical activity over time}

Given that the mean PA levels at baseline were high (> $250 \mathrm{~min} /$ week), a secondary aim was to examine whether there was an effect of baseline PA on the change in PA over time and to determine whether this differed by treatment arm. After adjusting for gender, race, and armband wear time, baseline PA significantly predicted the 2 -year change in PA. Those with lower bout-related MVPA at baseline had more favorable changes in bout-related MVPA across the 2 -year period $(\beta=-0.38, p<0.001)$. For example, averaged across treatment arms, participants engaging in $<250 \mathrm{~min} /$ week of bout-related MVPA at baseline $(n=352)$ increased MVPA at 4 months $(N=335,97.3 \pm 186.9 \mathrm{~min} /$ week), 1 year 


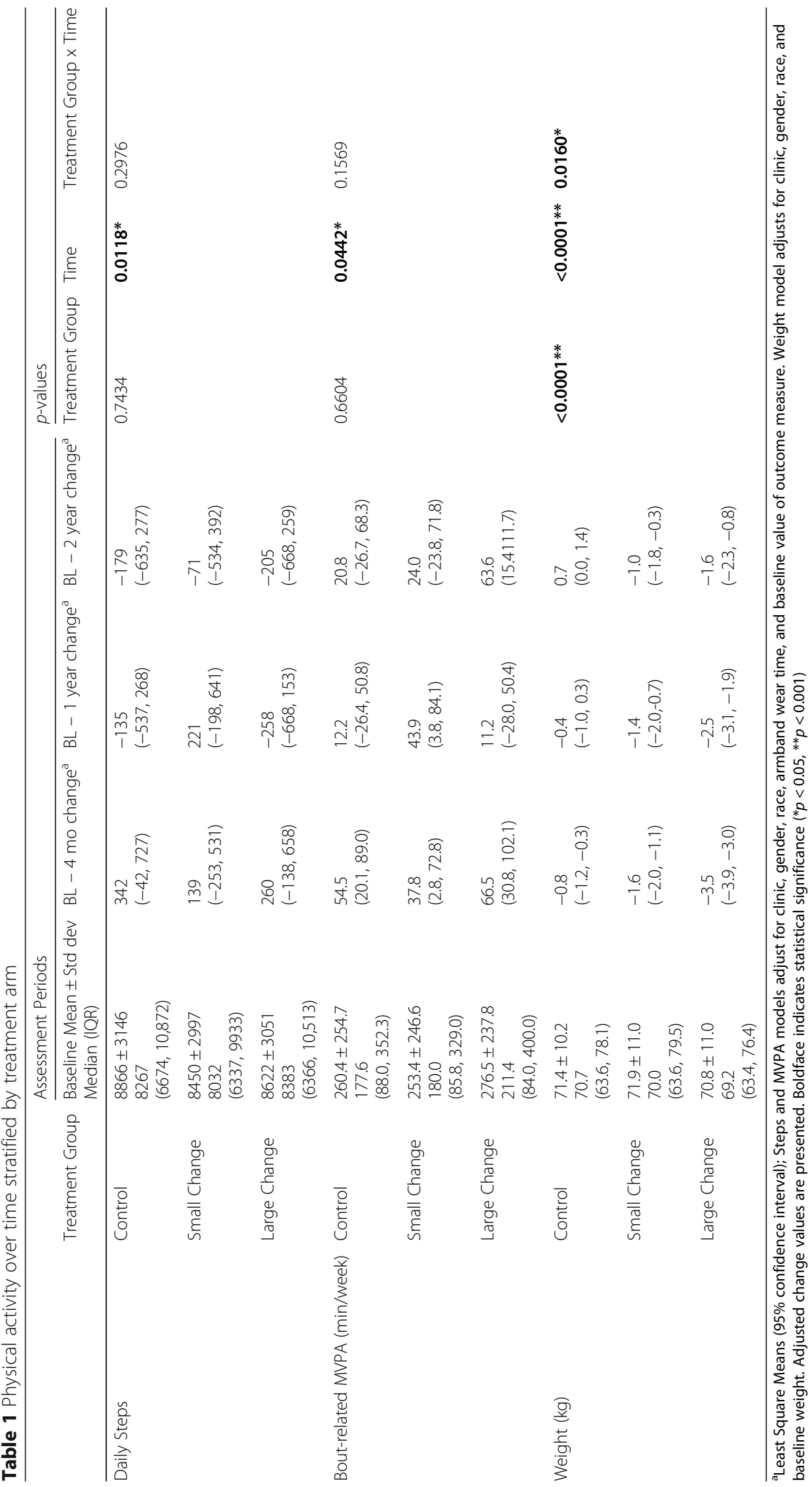


Table 2 Percentage of participants meeting intervention PA recommendations

\begin{tabular}{|c|c|c|c|c|c|c|c|c|}
\hline & \multirow[b]{2}{*}{ Treatment Group } & \multicolumn{4}{|c|}{ Assessment Periods } & \multicolumn{3}{|l|}{$p$-values } \\
\hline & & Baseline & 4 months & 1 year & 2 years & Treatment Group & Time & Treatment Group x Time \\
\hline \multirow[t]{3}{*}{$\geq 250 \mathrm{~min} /$ week of bout-related MVPA } & Control & 81 (40.3\%) & $83(43.2 \%)$ & $65(40.0 \%)$ & $63(41.5 \%)$ & 0.2949 & 0.4872 & 0.1460 \\
\hline & Small Change & $74(37.2 \%)$ & $82(45.6 \%)$ & $67(44.7 \%)$ & $56(37.6 \%)$ & & & \\
\hline & Large Change & $88(45.1 \%)$ & $98(55.4 \%)$ & 65 (40.9\%) & $71(46.7 \%)$ & & & \\
\hline \multirow[t]{3}{*}{ Increase daily steps by $\geq 2000$ steps/day } & Control & - & $32(16.7 \%)$ & $25(15.3 \%)$ & $31(20.4 \%)$ & 0.1859 & 0.5124 & 0.8087 \\
\hline & Small Change & - & $44(24.4 \%)$ & $39(26.0 \%)$ & $34(22.8 \%)$ & & & \\
\hline & Large Change & - & $40(22.6 \%)$ & $35(22.0 \%)$ & $32(21.1 \%)$ & & & \\
\hline
\end{tabular}

$\mathrm{N}(\%)$; Models adjusted for clinic, gender, race, armband wear time, and baseline value of outcome measure

$(N=287,72.8 \pm 182.7 \mathrm{~min} /$ week $)$, and 2 years $(N=274$, $98.0 \pm 251.3 \mathrm{~min} /$ week), while those engaging in $\geq 250 \mathrm{~min} /$ week at baseline $(n=243)$ had reductions in MVPA at each of these time points $(4 \mathrm{mo}: N=228,-32.9 \pm 295.4,1$ year: $N=208,-75.6 \pm 340.9,2$ years: $N=200,-73.5 \pm 444.8 \mathrm{~min} /$ week). Similarly, those with lower daily steps at baseline had more favorable changes in daily steps from baseline to 2 years $(\beta=-0.42, p<0.001)$. The effect of baseline PA on the change in PA over time was similar in the 3 treatment arms (daily steps: $p=0.59$; MVPA: $p=0.29$ ).

\section{Effect of physical activity on weight change over time}

Another aim was to examine the relationship between PA and weight change across the intervention period. Although the SNAP primary outcome paper has already reported on changes in body weight across treatment arms [15], weight data for the current sample are shown in Table 1. We compared daily steps and bout-related MVPA among participants gaining $>1 \mathrm{lb}$. from baseline to 2 years $(n=187)$ to those who lost weight or gained $\leq 1 \mathrm{lb}$. over this same time period $(n=285)$. Participants with a 2 -year weight gain $>1 \mathrm{lb}$. engaged in less bout-related MVPA at 4 months, 1 year and 2 years, compared to those not gaining $>1 \mathrm{lb}$. over this time period (Table 3). Further mixed effects models, adjusting for demographic variables, treatment group, dietary intake, and baseline values, revealed the change in MVPA across all time points differed by an average of $47.8 \mathrm{~min} /$ week between those gaining $>1 \mathrm{lb}$. and those who did not $(p=0.0125)$. There was no significant difference in daily steps at 4 months, 1 year, or 2 years between those gaining $>1 \mathrm{lb}$. and those gaining $\leq 1 \mathrm{lb}$. at year $2(p$ 's $>0.10)$.

To further investigate the relationship between change in PA and change in weight, we used a categorical approach, examining how different patterns of PA change between 4 months (i.e., the end of the intensive intervention phase) to 2 years were related to weight change over this same time period. Participants were categorized into 1 of $4 \mathrm{PA}$ groups based upon their achievement of $\geq 250 \mathrm{~min} /$ week of bout-related MVPA at 4 months and 2 years: 1) 'Nonadopt': <250 min/week at 4 months and 2 years, 2) 'Late adopt': $<250 \mathrm{~min} /$ week at 4 months, but $\geq 250 \mathrm{~min} /$ week at 2 years, 3) 'Maintain': $\geq 250 \mathrm{~min} /$ week at 4 months and
2 years, and 4) 'Non-maintain': $\geq 250 \mathrm{~min} /$ week at 4 months but $<250 \mathrm{~min} /$ week at 2 years (Fig. 1a). Similar categories were formed using the SC daily step goal, stratifying participants based upon whether they had $\mathrm{a} \geq 2000$ steps/day increase from baseline at both 4 months and 2 years (Fig. 1b). There was a significant group $\mathrm{x}$ time interaction effect for bout-related MVPA category on weight change over time $(p=0.0002)$. Independent of 4-month MVPA levels, participants engaging in $<250 \mathrm{~min} /$ week at 2 years ('Non-adopt' and 'Non-maintain' groups) regained all of their weight from 4 months to 2 years, while those engaging in $\geq 250 \mathrm{~min} /$ week at Year 2 ('Late adopt' and 'Maintain' groups) had a mean weight loss of $1.5-2.0 \mathrm{~kg}$ at Year 2 . There was not a significant group $\mathrm{x}$ time interaction effect when participants were categorized based upon steps.

Finally, we explored whether engagement in $\geq 250 \mathrm{~min} /$ week of bout-related MVPA $(n=181)$ was associated with more favorable changes in weight at 2 years, compared to 150 to $<250(n=87)$ and $0-150 \mathrm{~min} /$ week $(n=176)$. Twoyear weight change among participants engaging in $\geq 250 \mathrm{~min} /$ week $(-1.83 \pm 4.24 \mathrm{~kg})$ was not significantly different from those engaging in 150 to $<250 \mathrm{~min} /$ week $(-0.78 \pm$ $4.84 \mathrm{~kg} ; p=0.11$ ) but was significantly greater than those engaging in $0-150 \mathrm{~min} /$ week $(-0.06 \pm 4.69 \mathrm{~kg} ; p=0.0001)$. Of note, $<150$ and 150 to $<250 \mathrm{~min} /$ week groups were not significantly different from one another $(p=0.11)$. Further, $30.4 \%$ of participants engaging in $\geq 250 \mathrm{~min} /$ week gained $>1 \mathrm{lb}$. at year 2, which was significantly lower than the $49.4 \%$ observed in the $0-150 \mathrm{~min} /$ week group $(p=0.0002)$, but not significantly different from those engaging in 150 to $<250 \mathrm{~min} /$ week at year $2(35.6 \% ; p=0.40)$. This percentage was also significantly higher in the 150 to $<250$ group, relative to the $<150 \mathrm{~min} /$ week group $(p=0.03)$.

\section{Discussion}

The SNAP trial examined the effectiveness of two different self-regulation approaches to weight gain prevention, relative to a control condition, in a large cohort of young adults. The primary outcome paper focused on changes in weight [15] - here we examine whether changes in objectively-assessed PA differed by treatment arm. Overall, the change in daily steps and bout-related MVPA over two years did not differ among SC, LC, or SG. When collapsed 


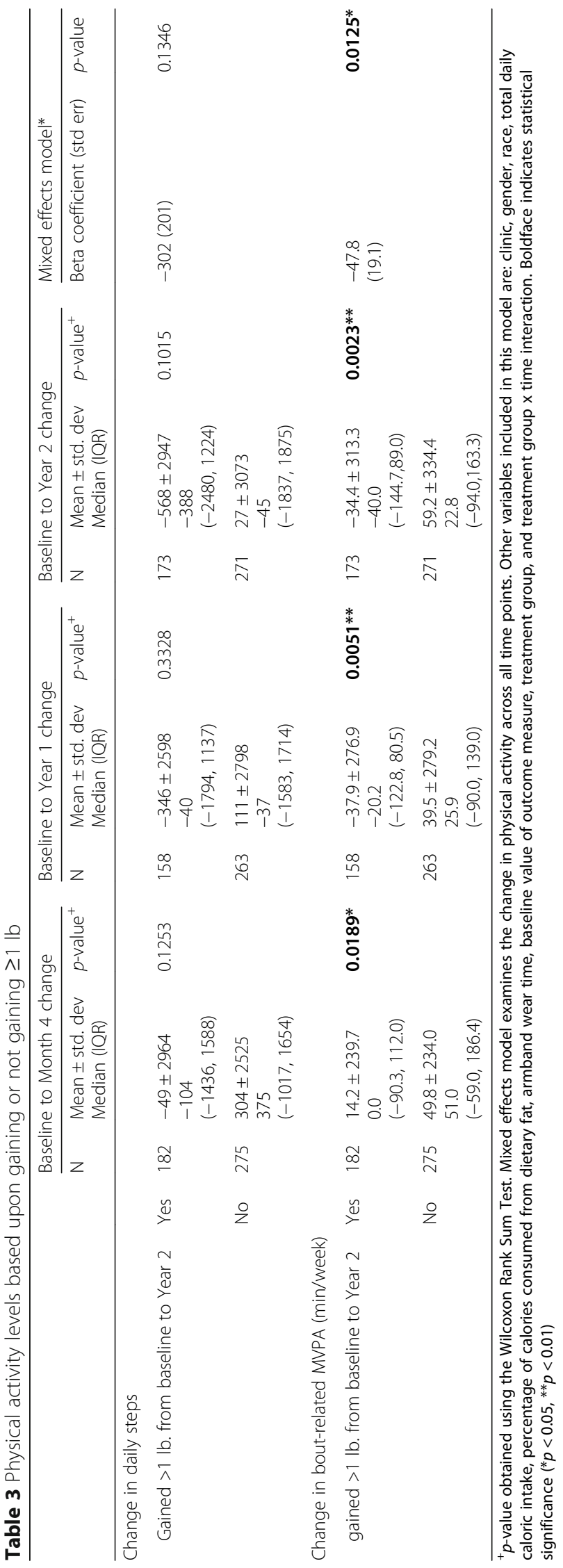




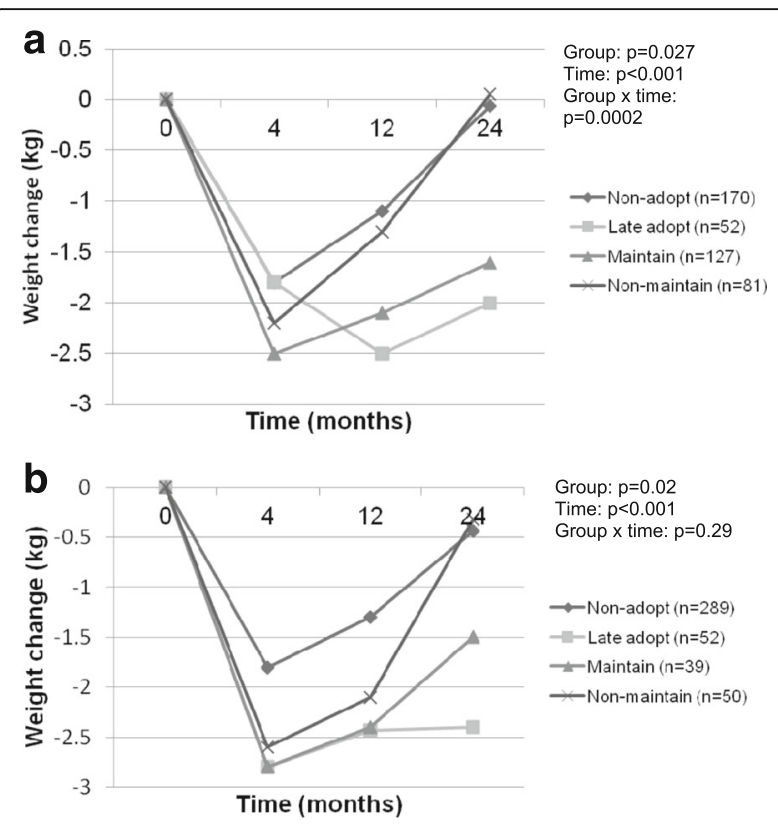

Fig. 1 a Title: Categorization of participants based upon achievement of $\geq 250 \mathrm{~min} /$ week at 4 months and 2 years. a Legend: 'Non-adopt': $<250 \mathrm{~min} /$ week at 4 months and 2 years; 'Late adopt': $<250 \mathrm{~min} /$ week at 4 months, but $\geq 250 \mathrm{~min} /$ week at 2 years; 'Maintain': $\geq 250 \mathrm{~min} /$ week at 4 months and 2 years; 'Non-maintain': $\geq 250 \mathrm{~min} /$ week at 4 months but $<250 \mathrm{~min} /$ week at 2 years. Model adjusts for clinic, gender, race, dietary intake, baseline weight, and baseline PA. b Title: Categorization of participants based upon achievement of $\geq 2000$ steps/day above baseline at 4 months and 2 years. $\mathbf{b}$ Legend: Non- adopt: $<2000$ step increase above baseline at 4 months and 2 years; Late Adopt: $<2000$ step increase above baseline at 4 months but $>=2000$ step increase at 2 years; Maintain: > = 2000 step increase above baseline steps at 4 months and 2 years; Non-maintain: > = 2000 step increase above baseline at 4 months and $<2000$ step increase above baseline at 2 years. Model adjusts for clinic, gender, race, dietary intake, baseline weight, and baseline steps

across treatment arms, the greatest improvement in PA was observed at 4 months. On average, participants increased bout-related MVPA by $50 \mathrm{~min} /$ week, which given the high PA levels observed at baseline, equated to over $300 \mathrm{~min} /$ week of bout-related MVPA at Month 4.

To date, few studies have examined changes in PA among young adults within the context of a lifestyle intervention and the SNAP trial was the first to examine this within a weight gain prevention trial. The IDEA study assessed the effect of a standard behavioral weight loss program for overweight and obese young adults on changes in objectively-assessed PA over 6 months [25]. Study participants were given an exercise goal of $300 \mathrm{~min} /$ week of MVPA. While IDEA participants were less active than SNAP participants at baseline (100 min/week vs. $263 \mathrm{~min} /$ week of bout-related MVPA), IDEA participants significantly increased bout-related MVPA to $215 \mathrm{~min} /$ week at 6 months. While the current study also reported increases in MVPA, although to a lesser degree than the IDEA study, SC and LC intervention approaches were no more effective at increasing MVPA than the SG group. Although we can't say with certainty why the 3 groups did not differ on changes in PA, we hypothesize that this may be attributed to the fact that PA was only a small component of the SC or LC interventions. Specifically, only 1 of the 8 initial weekly intervention sessions in SC and LC focused on PA. Conversely, SG participants were provided with an overview of the principles of both the LC and SC approaches at one intervention session and encouraged to select whichever approach they felt would be most effective for them. Therefore, they were given the same general instructions for increasing $\mathrm{PA}$ as $\mathrm{SC}$ and $\mathrm{LC}$, possibly explaining why similar changes in PA were observed between treatment groups. These findings suggest that for individuals enrolled in a program to prevent weight gain and who are taught that it is important to increase PA to achieve this goal, will do so, at least temporarily.

A secondary aim of this study was to examine the relationship between PA and weight change within the context of an intervention. While changes in PA were associated with changes in weight, this relationship did not differ by treatment group. We previously reported that $a \geq 1 \mathrm{lb}$. weight gain was associated with worsened cardiometabolic outcomes compared to weight loss or $<1 \mathrm{lb}$. weight gain [26]. Given the clinical significance of gaining $>1 \mathrm{lb}$., this paper examined whether there were differences in PA between these post-hoc weight groupings. Participants who lost weight or gained $\leq 1 \mathrm{lb}$. at year 2 had a $59 \mathrm{~min} /$ week increase in MVPA above baseline levels at year 2 , while those participants who gained $>1 \mathrm{lb}$. had a $34 \mathrm{~min} /$ week decrease in MVPA; differences in boutrelated MVPA between these post-hoc weight groups were also observed at 4 months and 1 year. These results remained after adjusting for dietary intake. Interestingly, there was no difference in daily steps between those who gained $>1 \mathrm{lb}$. and those who did not. This suggests that more structured exercise of at least moderate intensity may be more important than lifestyle activities for preventing weight gain; thus weight gain prevention programs should consider targeting changes in boutrelated MVPA.

In addition to looking at differences in PA by post-hoc weight change groups, we also examined whether achievement of $\geq 250 \mathrm{~min} /$ week of MVPA was associated with weight change. While the percentage of participants achieving this threshold of PA at all time points did not differ by treatment group, when collapsed across treatment groups, achievement of $\geq 250 \mathrm{~min} /$ week at Year 2 was associated with improved 2-year weight outcomes when compared to those achieving < $250 \mathrm{~min} /$ week. Moreover, this association persisted, regardless of bout-related MVPA at 4 months or dietary intake. However, follow-up analyses revealed that those achieving $\geq 250 \mathrm{~min} /$ week at 
year 2 lost approximately $1 \mathrm{~kg}(2.3 \mathrm{lbs})$ more than those engaging in 150 to $<250 \mathrm{~min} /$ week of MVPA, which was not statistically significant. These data suggest that PA levels $\geq 150 \mathrm{~min} /$ week are also effective for preventing weight gain. This level of PA is consistent with recommendations from the American College of Sports Medicine for weight gain prevention, which state that there is sufficient evidence that 150-250 min/week of MVPA is sufficient to prevent weight gain greater than $3 \%$ in most adults [10]. The current findings confirm this recommendation in a sample of young adults, and expand upon this recommendation through the use of objective PA monitors, versus self-report measures of PA. Thus future weight gain prevention efforts in young adults should target $\geq 150 \mathrm{~min} /$ week of MVPA.

Unlike bout-related MVPA, achievement of $\geq 10,000$ steps/day was not associated with weight change. While daily steps encompass both light intensity and MVPA, it appears that bout-related MVPA may be the greatest contributor for preventing weight gain. However, it should be noted that a greater percentage of SNAP participants achieved and maintained the MVPA threshold for PA than those who achieved and maintained $\geq 10,000$ steps/day. Thus it is possible that achievement of a different threshold of daily steps may be more closely related to weight change.

Overall, SNAP participants were highly active at baseline - mean MVPA levels were $>250 \mathrm{~min} /$ week and over $40 \%$ of participants met this threshold of PA. It is unclear whether this magnitude of PA is common for young adults of this BMI, or whether young adults enrolling in a weight gain prevention trial may be more likely to engage in higher levels of PA. Unfortunately, few studies have objectively-assessed MVPA among young adults. Overweight and obese young adults participating in a weight loss study (IDEA Study), engaged in $>150$ fewer min/week compared to SNAP participants at baseline [25]; however it is uncertain how much of this difference can be attributed to differences in BMI between study participants. Similarly in a population-based study, Tucker et al. reported that only $10.8 \%$ of young adults aged $20-29$ engage in an 'adequate' amount of MVPA according to guidelines; however obese individuals were also included in these estimates [6]. Therefore, whether baseline PA among SNAP participants is 'typical' of young adults in this BMI range cannot be determined.

The final aim of this study was to examine the effect of baseline PA on change in PA over time. Baseline PA was a significant moderator of change in PA, with higher baseline PA associated with less favorable changes in PA over the intervention period. For example, participants in the current study who engaged in $<250 \mathrm{~min} /$ week at baseline increased PA by approximately $100 \mathrm{~min} /$ week at 4 months while those with PA levels $\geq 250 \mathrm{~min} /$ week at baseline reduced PA by an average of $33 \mathrm{~min} /$ week. This suggests that self-regulation approaches for weight gain prevention used in the current study can effectively increase PA among those with lower levels of PA at baseline; however additional intervention strategies may be needed within the context of weight gain prevention programs in order to promote maintenance of PA in those with high baseline levels. This is an important and interesting area of research which warrants further investigation, particularly given that PA is typically reduced throughout young adulthood, and our findings which demonstrated that a reduction in PA between months 4 and 24 was associated with weight gain. Novel strategies for promoting the maintenance of PA in this population should be explored given that the PA prescriptions used in the current study led to small reductions in PA among highly active individuals.

This study answers a novel research question related to weight gain prevention in young adults and has numerous strengths including a large sample size and unique population. It is further strengthened by the fact that it was addressed within a randomized trial, it included long-term follow-up data, and PA was assessed objectively and not via self-report measures. However, it is not without limitations. It is possible that the findings from this study would not be generalizable to the entire young adult population given that study participants may have been more motivated or health conscious, contributing to their decision to enroll in a weight gain prevention trial. Further, study participants were highly active, and predominately female and white. Finally, the findings highlighting the relationship between PA and weight change were performed posthoc and thus future studies should be designed to examine the optimal dose of PA for weight gain prevention.

\section{Conclusions}

In conclusion, this study suggests that both Small Changes (prescribed to increase steps by 2000 steps/day) and Large Changes (prescribed to increase bout-related MVPA to $\geq 250 \mathrm{~min} /$ week) PA recommendations led to similar increases in bout-related MVPA and daily steps, yet these changes were no different than those observed in the Self-guided group. This suggests that a brief intervention with general PA recommendations, as provided to Self-guided participants, may be sufficient for increasing PA at least temporarily among a group of active young adults who are concerned about weight gain. Moreover, study findings indicate that regardless of group assessment, better weight gain prevention over 2 years is associated with higher levels of bout-related MVPA, but not daily steps. Therefore, future weight gain prevention interventions should consider targeting boutrelated MVPA and not daily steps. 


\section{Appendix 1}

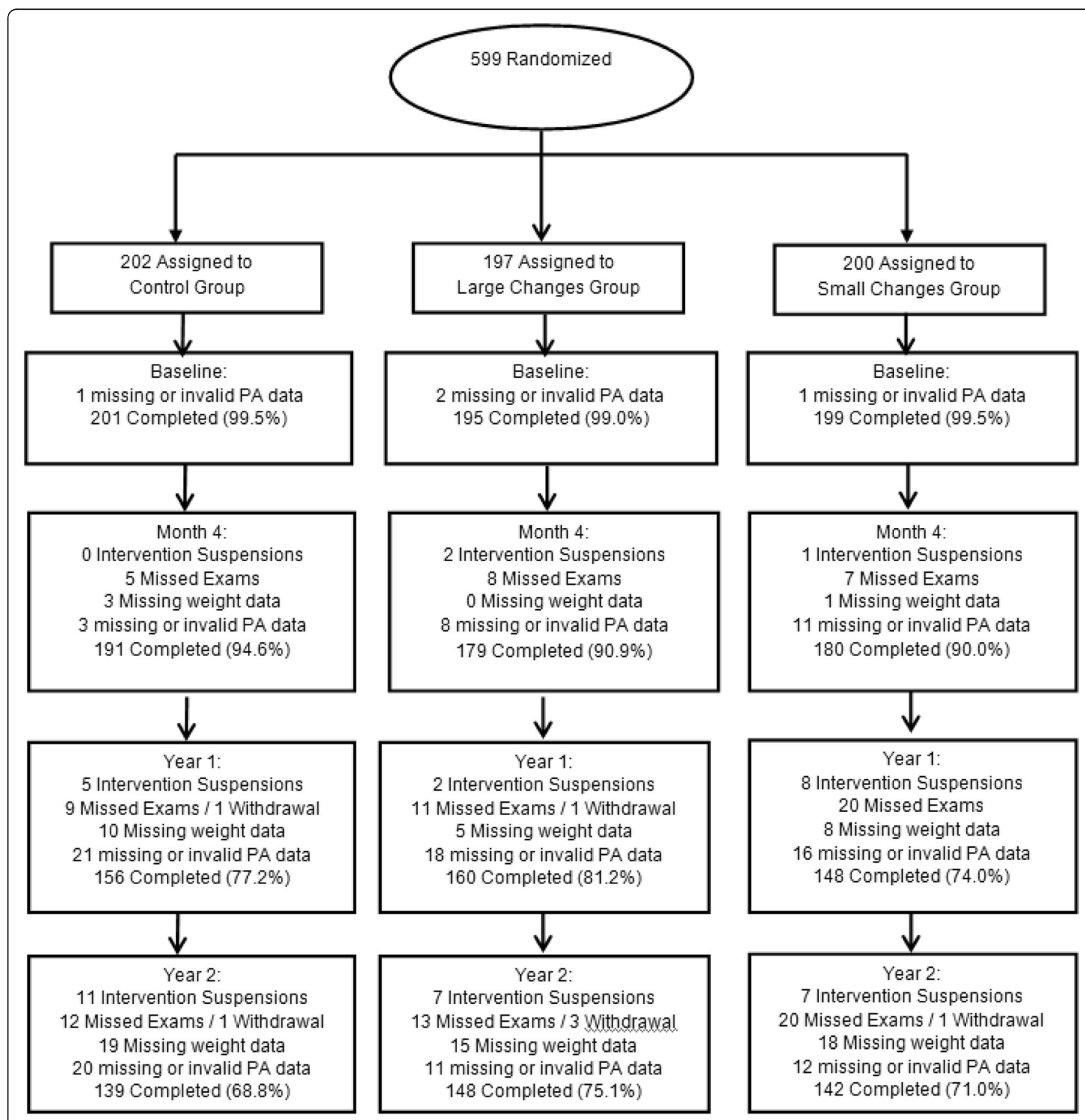

Fig. 2 Flow of participants through the study 


\section{Additional file}

Additional file 1: CONSORT 2010 checklist of information to include when reporting a randomised trial*. (PDF $76 \mathrm{~kb}$ )

\section{Acknowledgements}

We would like to acknowledge the contributions of the entire SNAP research group

\section{SNAP Research Group}

Clinical Sites

The Miriam Hospital/Brown Medical School Rena R. Wing, PhD'; Erica

Ferguson, BS, RD²; Kristen Annis; Ryan Busha; Isabella Cassell; Eva Chen;

Pamela Coward, MS, RD; Jose DaCruz; Caitlin Egan, MS; Brittany James; Marie Kearns; Angelica McHugh; Kevin O'Leary; Kathy Palmer; Deborah Ranslow-

Robles; Kathryn Story; Jennifer Trautvetter; Jessica Unick; Samantha Williams; Carolyn Wunsch; Annajane Yolken.

The University of North Carolina at Chapel Hill Deborah Tate, PhD'; Karen E. Hatley, MPH, RD²; Candace Alick; Loneke Blackman, RD; Rachel Bordogna, RD; Melissa Crane, PhD; Molly Diamond, MPH;. Kristen Polzien, PhD; Keneisha Quick; Brooke Tompkins Nezami, PhD; Carmina Valle, PhD;

Consultants

University of Alabama at Birmingham Cora E. Lewis, MD, MSPH University of Connecticut Amy Gorin, $\mathrm{PhD}^{3}$.

Virginia Commonwealth University, School of Medicine Jessica G LaRose, PhD ${ }^{3}$. Coordinating Center

Wake Forest School of Medicine Mark A. Espeland, PhD'; Letitia H. Perdue, MS $^{2}$; Judy L. Bahnson, BA, CCRP ${ }^{3}$; Wei Lang, PhD³ ; Cheryl Bentley; Patty Davis, BS; Katelyn Garcia, MS; Leah P. Griffin, MS; Lea Harvin, BS; Rebecca H. Neiberg, MS; Julia Robertson, BS.

\section{Central Resources Centers}

Central Laboratory, Northwest Lipid Metabolism and Diabetes Research

Laboratories Santica M. Marcovina, PhD, ScD'; Jessica Hurting ${ }^{2}$; Vinod Gaur, PhD Federal Sponsors

National Heart, Lung, and Blood Institute S. Sonia Arteaga, PhD; Catherine

Loria, PhD, MS, FAHA.

${ }^{1}$ Principal Investigator.

${ }^{2}$ Program Coordinator.

${ }^{3}$ Co-Investigator.

All other SNAP staff members are listed alphabetically by site.

\section{Funding}

This work was supported by a grants (U01HL090864 and U01HL090875) from the National Heart, Lung, and Blood Institute, National Institutes of Health. This study is registered at www.clinicaltrials.gov (NCT01183689). The opinions experienced here are those of the investigators and do not necessarily reflect the views of the funding agency.

\section{Availability of data and materials}

The datasets used and/or analyzed during this study are available from the corresponding author upon reasonable request.

\section{Authors' contributions}

RRW was responsible for the study design and grant submission and oversees the study at The Miriam Hospital; DFT collaborated on the study design and grant submission and oversees the study at the University of North Carolina; MAE collaborated on the study design and grant submission and oversees the Coordinating Center at Wake Forest School of Medicine; JLU was responsible for the conceptual design of this manuscript and drafting this manuscript; WL conducted the data analyses; SEW and CME assisted with data collection; JLU, WL, SEW, DSB, CME, MAE, RRW, and DFT made substantially contributed to the interpretation of the data and revision of this manuscript. All authors read and approved the final version of the submitted paper.

\section{Ethics approval and consent to participate}

Informed consent was obtained from all participants, and procedures were performed in accordance with The Miriam Hospital's (Providence, RI) and University of North Carolina (Chapel Hill, NC) Institutional Review Boards.

\section{Consent for publication}

Not applicable.

\section{Competing interests}

Dr. Tate is on the Weight Watchers Scientific Advisory Board and received a research grant from Weight Watchers International. The remaining authors have no conflicts of interest to declare. Further, this study was sponsored by $\mathrm{NHLBI}$ and the study sponsor did not have any role in the study design; collection, analysis, and interpretation of data; writing the report; and the decision to submit the report for publication.

\section{Publisher's Note}

Springer Nature remains neutral with regard to jurisdictional claims in published maps and institutional affiliations.

\section{Author details}

'Brown University and the Miriam Hospital's Weight Control and Diabetes Research Center, 196 Richmond Street, Providence, RI 02903, USA. Wake Forest School of Medicine, Winston-Salem, NC, USA. ${ }^{3}$ University of North Carolina, Gillings School of Global Public Health, Chapel Hill, NC, USA.

Received: 7 August 2017 Accepted: 20 November 2017

Published online: 04 December 2017

\section{References}

1. Ball K, Brown W, Crawford D. Who does not gain weight? Prevalence and predictors of weight maintenance in young women. Int J Obes Relat Metab Disord. 2002;26(12):1570-8.

2. Truesdale KP, Stevens J, Lewis CE, Schreiner PJ, Loria CM, Cai J. Changes in risk factors for cardiovascular disease by baseline weight status in young adults who maintain or gain weight over 15 years: the CARDIA study. Int J Obes. 2006;30(9):1397-407.

3. Norman JE, Bild D, Lewis CE, Liu K, West DS, Study C. The impact of weight change on cardiovascular disease risk factors in young black and white adults: the CARDIA study. Int J Obes Relat Metab Disord. 2003;27(3):369-76.

4. Freedman DS, Khan LK, Serdula MK, Dietz WH, Srinivasan SR, Berenson GS. The relation of childhood BMI to adult adiposity: the Bogalusa heart study. Pediatrics. 2005;115(1):22-7.

5. Singh AS, Mulder C, Twisk JW, van Mechelen W, Chinapaw MJ. Tracking of childhood overweight into adulthood: a systematic review of the literature. Obes Rev. 2008;9(5):474-88.

6. Tucker JM, Welk GJ, Beyler NK. Physical activity in U.S.: adults compliance with the physical activity guidelines for Americans. Am J Prev Med. 2011; 40(4):454-61.

7. Keating XD, Guan J, Pinero JC, Bridges DMA. Meta-analysis of college students' physical activity behaviors. J Am Coll Heal. 2005;54(2):116-25.

8. Lewis CE, Jacobs DRJ, McCreath H, Kiefe Cl, Schreiner PJ, Smith DE, et al. Weight gain continues in the 1990s: 10-year trends in weight and overweight from the CARDIA study. Coronary artery risk development in young adults. Am J Epidemiol. 2000;151(12):1172-81.

9. Williamson DF, Kahn HS, Remington PL, Anda RF. The 10-year incidence of overweight and major weight gain in US adults. Arch Intern Med. 1990; 150(3):665-72

10. Donnelly JE, Blair SN, Jakicic JM, Manore MM, Rankin JW, Smith BK. American College of Sports Medicine position stand. Appropriate physical activity intervention strategies for weight loss and prevention of weight regain for adults. Med Sci Sports Exerc. 2009:41(2):459-71.

11. Leslie E, Fotheringham MJ, Owen N, Bauman A. Age-related differences in physical activity levels of young adults. Med Sci Sports Exerc. 2001;33(2):255-8.

12. Bell $\mathrm{S}$, Lee $\mathrm{C}$. Emerging adulthood and patterns of physical activity among young Australian women. Int J Behav Med. 2005;12(4):227-35.

13. Brown WJ, Trost SG. Life transitions and changing physical activity patterns in young women. Am J Prev Med. 2003;25(2):140-3.

14. Sallis JF, Saelens BE. Assessment of physical activity by self-report: status, limitations, and future directions. Res Q Exerc Sport. 2000;71(2 Suppl):S1-14.

15. Wing RR, Tate DF, Espeland MA, Lewis CE, LaRose JG, Gorin AA, et al. Innovative self-regulation strategies to reduce weight gain in young adults: the study of novel approaches to weight gain prevention (SNAP) randomized clinical trial. JAMA Intern Med. 2016;176(6):755-62.

16. Tate DF, LaRose JG, Griffin LP, Erickson KE, Robichaud EF, Perdue L, et al. Recruitment of young adults into a randomized controlled trial of weight gain prevention: message development, methods, and cost. Trials. 2014;15:326. 
17. Wing RR, Tate D, Espeland M, Gorin A, LaRose JG, Robichaud EF, et al. Weight gain prevention in young adults: design of the study of novel approaches to weight gain prevention (SNAP) randomized controlled trial. BMC Public Health. 2013;13:300.

18. Kuller LH, Simkin-Silverman LR, Wing RR, Meilahn EN, Ives DG. Women's healthy lifestyle project: a randomized clinical trial: results at 54 months. Circulation. 2001;103(1):32-7.

19. Block G, Hartman A, Dresser C, Carroll M, Gannon J, Gardner LA. Data-based approach to diet questionnaire design and testing. Am J Epidemiol. 1986; 124:453-69.

20. Jakicic JM, Marcus M, Gallagher Kl, Randall C, Thomas E, Goss FL, et al. Evaluation of the SenseWear pro armband to assess energy expenditure during exercise. Med Sci Sports Exerc. 2004;36(5):897-904.

21. St-Onge M, Mignault D, Allison DB, Rabasa-Lhoret R. Evaluation of a portable device to measure daily energy expenditure in free-living adults. Am J Clin Nutr. 2007;85(3):742-9.

22. Unick JL, Bond DS, Jakicic JM, Vithiananthan S, Ryder BA, Roye GD, et al. Comparison of two objective monitors for assessing physical activity and sedentary behaviors in bariatric surgery patients. Obes Surg. 2012;22(3):347-52.

23. Garber CE, Blissmer B, Deschenes MR, Franklin BA, Lamonte MJ, Lee IM, et al. American College of Sports Medicine position stand. Quantity and quality of exercise for developing and maintaining cardiorespiratory, musculoskeletal, and neuromotor fitness in apparently healthy adults: guidance for prescribing exercise. Med Sci Sports Exerc. 2011;43(7):1334-59.

24. Tudor-Locke C, Bassett DRJ. How many steps/day are enough? Preliminary pedometer indices for public health. Sports Med. 2004;34(1):1-8.

25. Jakicic JM, King WC, Marcus MD, Davis KK, Helsel D, Rickman AD, et al. Short-term weight loss with diet and physical activity in young adults: the IDEA study. Obesity (Silver Spring). 2015;23(12):2385-97.

26. Wing R, Tate D, Garcia K, BA. B, Lewis CE, Gorin A, et al. Innovative selfregulation strategies reduce weight gain and improve cardiovascular risk factors in young adults: The Study of Novel Approaches to Weight Gain Prevention (SNAP). Orleans: The 34th Annual Scientific Meeting of The Obesity Society; 2016.

\section{Submit your next manuscript to BioMed Central and we will help you at every step:}

- We accept pre-submission inquiries

- Our selector tool helps you to find the most relevant journal

- We provide round the clock customer support

- Convenient online submission

- Thorough peer review

- Inclusion in PubMed and all major indexing services

- Maximum visibility for your research

Submit your manuscript at www.biomedcentral.com/submit
Biomed Central 